\title{
Examining the effect of an aerobic exercise program on stress and triglycerides level in sedentary students - A pilot study
}

\author{
Sinku Kumar Singh ${ }^{1}$, Nadeem Afroz ${ }^{2}$ \\ ${ }^{1}$ Department of Educational Sciences, SRTM University Nanded (MS), India \\ ${ }^{2}$ Mission Hospital, Durgapur (WB), India
}

\section{ABSTRACT}

Background: Stress is a risk factor for developing hypertension and cardiovascular diseases. The increased risk of cardiovascular diseases from chronic stress has been linked to increased plaque build-up as a result of elevated cholesterol, hardening of the arteries, change in the blood pressure, and abnormal working rhythm of the heart. The primary aim of this study was to examine the effects of Aerobic Exercise on stress and triglycerides.

Methods: This study is a Pre-experimental Study - One Group Pre-test Post-test Design. A group of 17 sedentary male students whose age ranged between 19-28 years was enrolled in the study. The respondents were free of any type of smoking habit, consumptions of alcohol and drugs before the study. The study respondents participated in Aerobic Exercise Training program which was conducted for six weeks, four days a week and 45 minutes in a day. The pre-test and post-test were conducted before and after the intervention.

Results: The mean age, height and weight of the Sedentary Students were 24.34 years, $172.31 \mathrm{~cm}$ and 69.22 kg respectively.

Before an aerobic exercise program, 52.94\% sedentary students reported mild stress, $29.41 \%$ reported moderate stress and $17.64 \%$ reported severe stress. Whereas, after aerobic exercise program, $58.82 \%$ sedentary students reported mild stress, $23.52 \%$ reported moderate stress and only $11.64 \%$ reported severe stress. The Pre-test mean score of Triglycerides was $147.649 \mathrm{mg} / \mathrm{dl}$ and the post test was $113.483 \mathrm{mg} / \mathrm{dl}$.

Conclusion: An aerobic exercise program may reduce stress and triglycerides levels in sedentary students. This research provides a platform for further research in this field with higher power and precision.

Key words: Aerobic, Stress, Sedentary, Triglycerides

DOI: https://doi.org/10.3126/ijosh.v7i2.22891

\section{Introduction}

A sedentary lifestyle is one of the major causes of lifestyle disease around the world. Approximately two million deaths every year are attributable to sedentary lifestyle. ${ }^{1}$ The World Health Organization (WHO) study on risk factors and Mayo Clinic article suggest that sedentary lifestyle is one of the ten leading causes of death and disability in the world. 2,3 Physical inactivity increases the risk of mortality, doubles the risk of hyper and hypotension, cardiac related diseases, diabetes and obesity. ${ }^{4,5}$ The sedentary lifestyle is a

\section{Corresponding Author}

Dr. Sinku Kumar Singh,

Head, Department of Educational Sciences,

SRTM University Nanded (MS), India

E-mail: drsinkusingh@gmail.com

C 2017 IJOSH All rights reserved type of lifestyle with no irregular physical activity. Individuals working without any physical activity and they are sitting down all the time and usually, they only get up when its break time, meal time and going to the comfort room. They are always sitting down the whole day while doing their work. The sedentary life style (physical inactivity) is a seriously growing health problem in India. ${ }^{6}$ Anepidemiological study has shown that sedentary lifestyle will contribute to the early onset and progression of life style diseases such as cardiovascular disease, hypertension, diabetes and obesity. ${ }^{7}$ Stress is a contributing risk factor for developing cardiovascular diseases (CVD). The increased risk of CVD from chronic stress has been linked to increased plaque build-up as a result of elevated cholesterol, hardening of the arteries, change in the blood pressure, and abnormal working rhythm of the heart. ${ }^{8}$ Triglyceride is an ester derived 
from glycerol and three fatty acids. ${ }^{9}$ Triglyceride is constituents of body fat in human's bodies and other animals. ${ }^{10}$ Triglycerides are present in the blood to enable the bidirectional transference of adipose fat and blood glucose from the liver. ${ }^{11}$ Triglycerides are fat in the blood, and a high triglyceride level can increase the risk of heart related disease. In the human body, high levels of triglycerides in the bloodstream have been linked to atherosclerosis and, by extension, the risk of heart disease(Boston scientists) and stroke. ${ }^{12,13}$ There is a scarcity of research reports on stress and triglycerides of sedentary students and require a very extensive effort. The effort made by the investigator can prove very useful for reducing stress and triglycerides.

\section{Methods}

In this study, the researchers followed the ethical guidelines, principles, and standards for studies conducted with human beings. The study included safeguards for protecting humans, which involve three major ethical principles: beneficence, respect for human dignity, and human justice.

Only one group was targeted as an intervention group, there was no control group. The 17 male sedentary students from SRTM University participated in the study and their age ranged between 19-28 years. This study is a Pre-experimental Study - One Group Pre-test Post-test Design. For assessment of Academic Stress, the Student-life Stress Inventory (SSI) was used. ${ }^{14}$ The inventory reflected students' life stress experiences, In addition, the blood sample collected from veins to measure Triglyceride (a type of lipid) by the technician of Sahyog Pathology lab Vishnupuri Nanded. This study involves an experiment of sedentary students on quasi-experimental research design. The data was collected through respondents in the form of different descriptive tests. The demographic information about, age, height, weight, daily smoking etc. was obtained before seeking responses. The National Cholesterol Education Program has set guidelines for triglyceride levels. ${ }^{6}$

\begin{tabular}{ccc}
\hline \multicolumn{2}{c}{ Level } & Interpretation \\
\cline { 1 - 2 }$(\mathbf{m g} / \mathbf{d L})$ & $(\mathbf{m m o l} / \mathrm{L})$ & \\
\hline$<150$ & $<1.70$ & Normal range - low risk \\
$150-199$ & $1.70-2.25$ & Slightly above normal \\
$200-499$ & $2.26-5.65$ & Some risk \\
\hline 500 or higher & $>5.65$ & Very high - high risk \\
\hline
\end{tabular}

These levels are tested after fasting 8 to 12 hours.
For this study, the students studying in the Academic year 2016-2017 of Swami Ramanand Treeth Marathwada University's (NAAC 'A' Grade Government University) were selected as the study respondents. The study respondents participated in an aerobic exercise training program which was conducted for six weeks and four days in a week and 30 minutes in a day. Before exercise pre-test was done by the departmental fitness centre. Triglycerides (TD) were measured in Sahyog pathological laboratory. After the pre-test was over, all the selected subject were exposed to six week Exercise intervention program followed by post-test done by the departmental fitness centre. The program consisted of the following exercises; jogging, skipping, front-side-back running, floor push-ups, pull-ups, situps, back extension, squat etc.

\section{Data processing}

The data was checked for accuracy and completeness and was coded and put up into the Statistical Package for Social Sciences Descriptive statistics for all studied variables, percentage, mean, standard deviation (SD) and t-test was perform and were considered statistically significant at 0.05 level.

\section{Results}

The results concerning this study were presented in the form of tables and suitable figures below.

Table 1: Morphological characteristic of sedentary students

\begin{tabular}{|c|c|c|c|}
\hline \multirow[b]{2}{*}{ S.No. } & \multirow[b]{2}{*}{$\begin{array}{l}\text { Morphological } \\
\text { Characteristics }\end{array}$} & \multicolumn{2}{|c|}{ Student } \\
\hline & & Mean & $\begin{array}{l}\text { Standard } \\
\text { Deviation }\end{array}$ \\
\hline & Age (Year) & 24.34 & 3.60 \\
\hline & Weight (Kg) & 69.22 & 4.76 \\
\hline & Height $(\mathrm{Cm})$ & 172.31 & 15.14 \\
\hline
\end{tabular}

The mean age of Sedentary Student was $24.34+3.60$, mean weight as $69.22+4.76 \mathrm{~kg}$, and the mean height was $172.31+15.14 \mathrm{~cm}$.

The result revealed that $82.35 \%$ sedentary students used internet on regular basis. Similarly, $11.76 \%$ sedentary students reported that they have smoked / drunk in the past.

Figure 1. shows the pre and post-test of rate of overall level of stress to sedentary students. Result revealed that before an aerobic exercise intervention, $52.94 \%$ sedentary students reported mild stress, $29.41 \%$ sedentary students reported moderate stress and $17.64 \%$ sedentary students reported severe stress. 


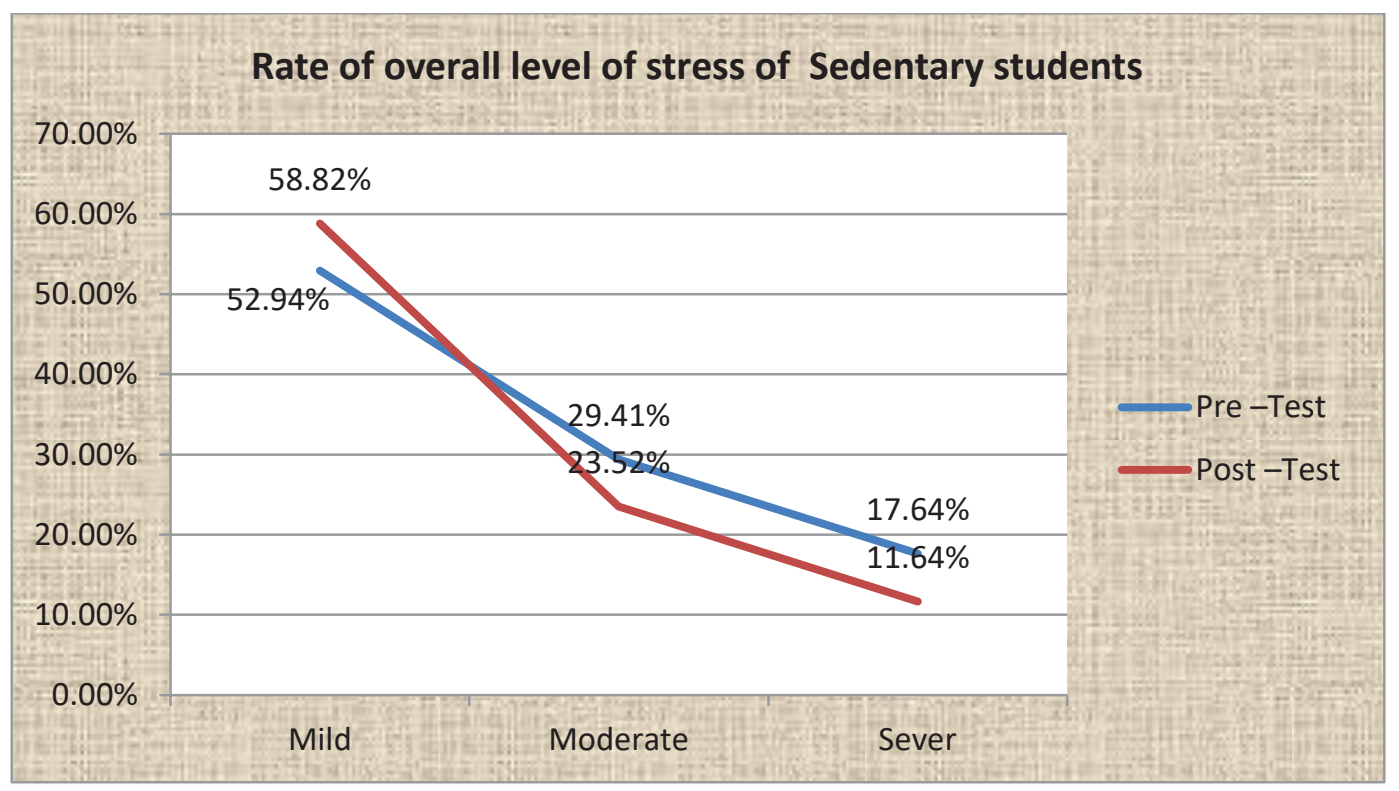

Figure 1: Rate of overall level of stress of sedentary students

Table 2: Pre and post-test of blood Pressure in Sedentary students

\begin{tabular}{lcccccc}
\hline Blood pressure & Stages & No. & Mean Scores & Standard Deviations & T-test & P - Value \\
\hline \multirow{2}{*}{ Systolic Blood Pressure } & Pre Test & 17 & 127.67 & 8.60 & \multirow{2}{*}{$1.78 \mathrm{NS}$} & 2.02 \\
& Post Test & 17 & 122.56 & 7.95 & & \\
\multirow{2}{*}{ Diastolic Blood Pressure } & Pre Test & 17 & 83.56 & 6.43 & \multirow{2}{*}{$1.23 \mathrm{NS}$} & 2.02 \\
& Post Test & 17 & 81.67 & 6.12 & & \\
\hline
\end{tabular}

Table 3: Pre and post-test of Triglycerides in sedentary students

\begin{tabular}{lcccccc}
\hline Components & Test & No. & Mean & Std. Deviation & T-value & P Value \\
\multirow{2}{*}{ Triglycerides } & Pre-test & 17 & 147.649 & 15.67 & \multirow{2}{*}{$6.921^{*}$} & 2.02 \\
& Post-test & 17 & 113.483 & 12.34 & & \\
\hline
\end{tabular}

Whereas, after aerobic exercise intervention, $58.82 \%$ sedentary students reported mild stress, $23.52 \%$ sedentary students reported moderate stress and only $11.64 \%$ sedentary students reported severe stress.

The Pre-test mean score of Systolic Blood Pressure (SBP) was $127.67 \mathrm{mmHg}$ and the post test was $122.56 \mathrm{mmHg}$ respectively for sedentary students. Furthermore, the Pre-test mean score of Diastolic Blood Pressure (DBP) was $83.56 \mathrm{mmHg}$ and the post test was $81.67 \mathrm{mmHg}$ respectively for sedentary students.

The Pre-test mean score of Triglycerides was 147.649 $\mathrm{mg} / \mathrm{dl}$ and the post test was $113.483 \mathrm{mg} / \mathrm{dl}$ obtained respectively of sedentary students. The findings of the study revealed that the mean values and SDs of Triglycerides decreased following an aerobic exercise intervention in sedentary students.

\section{Discussion}

The findings of the study indicates that though the mild stress level increased, the moderate and severe level stress of sedentary students have decreased after six weeks of an aerobic exercise intervention programme. Preliminary evidence suggests that physically active people have lower rates of stress and anxiety. Economos, Hildebrant and Hyatt, (2008), investigated that engaging in more physical activity improves psychosocial health and decreases stress. ${ }^{15}$ The several research have also shown that physical activity is an effective means of reducing anxiety and various indices of stress among adults. ${ }^{16,17}$ Exercise and other physical activity produce endorphins-chemicals in the brain that act as natural painkillers-and also improve the ability to sleep, which in turn reduces stress (Anxiety and depression association of America). Furthermore, the findings of the study revealed that the mean 
values and SDs of SBP and DBP have decreased, but there were no significant effects of aerobic exercise intervention program on SBP and DBP of sedentary students. The findings of the study revealed that aerobic exercises training intervention reduce triglycerides. Regular participation in physical activity as well as an exercise can positively alter cholesterol metabolism. Exercise is involved in increasing the production and action of several enzymes that function to enhance the reverse cholesterol transport system. Exercise has been shown to maintain blood pressure, lower the risk of cardiovascular heart disease and lowers Triglycerides. ${ }^{18}$ Most important effect of exercise on human body is on metabolic system specially lipids. Lipid and lipoprotein are risk factors for coronary heart diseases. ${ }^{18}$ Exercise favourably changes serum lipid lipoprotein-cholesterol concentration. The hormone cortisol is released in response to stress. Studies suggest that the high levels of cortisol from long-term stress can increase blood cholesterol, triglycerides, and blood pressure. These are common risk factors for heart diseases. This stress can also cause changes that promote the build-up of plaque deposits in the arteries. ${ }^{18-20}$ Even minor stress can trigger heart problems like poor blood flow to the heart muscle. This is a condition in which the heart doesn't get enough blood or oxygen. And, long-term stress can affect how the blood clots. This makes the blood stickier and increases the risk of stroke. An aerobic exercise

\section{References}

1. Bertrais S, Beyeme-Ondoua J.P, Czernichow S, Galan P, Hercberg S, Oppert, JM. Sedentary behaviors, physical activity, and metabolic syndrome in middle-aged French subjects. Obes. Res. 2005, 13(5): 936-44.

2. World Health Organization (2008).Urbanization and Health. Bulletin of the World Health Organization. Cited on: July 13 2016. Available from : https://www. who.int/bulletin/volumes/88/4/10-010410/en/

3. Mayo Clinic. (2014). Depression and anxiety: Exercise eases symptoms. Retrieved January 23, 2017. Available from http://www.mayoclinic.org/ diseases-conditions/depression/indepth/depressionand-exercise/art-20046495

4. Biddle SJH, Pearson N, Ross GM, Braithwaite R. Tracking of sedentary behaviours of young people: A systematic review. Prev Med (Baltim) 2010;51:34551

5. Briddle S.J, O"Connel S, Braithwaite R.F. Sedentary Behaviour Interventions in young people-analysis, British Journal of Sports Medicine. 56(11): 2655-67. program may reduce stress and triglycerides levels in sedentary students. This research provides a platform for further research in this field with higher power and precision.

\section{Limitation of the research}

Results of this study are limited by a relatively small preliminary experimental group rather than a study of actual behaviour, which would be very difficult to achieve. A limitation of this study is that it reflects the findings of one institution; the data was collected in one institution, hence, the results may not be generalized to other institutions. Future research is warranted on estimating the level of stress by psychometric instruments and large number of sample.

\section{Acknowledgments}

We own unbounded gratitude to Ph.D Research Scholar, Dr.Sandeip Gadadane, Dr. Rahul Sarode, Rahul Lahane, Amol Datar and Gulnaaz. They spared much of their valuable time and provided all possible help whenever required. We are thankful for the cooperation given by all sedentary students. Without their co-operation it was not possible for us to do the research on this sensitive topic. Finally thanks to all who helped us directly or indirectly in completion of this work.

6. Singh S. K. Cardiovascular fitness among sedentary students, Journal of exercise science and physiotherapy. 2012; 8( 2): 90-3.

7. Banerjee AK, Mandal A, Chanda D, Chakraborti S. Oxidant, antioxidant and physical exercise. Mol Cell Biochem 2003; 253(1:2): 30712.

8. Dimsdale, J. E. Psychological stress and cardiovascular disease. Journal of the American College of Cardiology (JACC). 2008;51(13), 1237-46

9. Nomenclature of Lipids. IUPAC-IUB Commission on Biochemical Nomenclature (CBN). European J. Biochem. 2 (1967) 127-1.

10. Nelson DL, Cox MM. (2000). Lehninger, Principles of Biochemistry (3rd ed.). New York: Worth Publishing. ISBN 1-57259-153-6.

11. Lampe, MA, Burlingame AL, Whitney J, Williams ML, Brown BE, Roitman E, Elias M. Human stratum corneum lipids: characterization and regional variations. J. Lipid Res. 1983; 24 (2): 12030. PMID 6833889.

12. Carolyn Y. Johnson. Boston scientists say triglycerides play key role in heart health. The 
Boston Globe. June18, 2014. Cited on Jan 14, 2017. Available from : https://www.bostonglobe. com/news/science/2014/06/18/boston-researchersfind-that-triglycerides-play-pivotal-role-heart-health/ ynrM4QQwlq1fCCoRwMfOAN/story.html

13. Drummond, K. E.; Brefere, L. M. (2014). Nutrition for Foodservice and Culinary Professionals (8th ed.). John Wiley \& Sons. ISBN 978-0-470-05242-6.

14. Bernadette M. Gadzella, William G. Masten. An analysis of the categories in the student-life stress inventory. American journal of psychological research. Jan 5, 2005; 1(1): 1-10.

15. Economos C, Hildebrant L, Hyatt, R. College Freshman Stress and Weight Change: Differences by Gender. American Journal of Health Behavior. 2008 Jan-Feb; 32(1)16-25.
16. Kawachi I. Stress and the heart: Psychosocial pathways to coronary heart disease BMJ. 2002 Jan 19; 324(7330): 176.

17. Dunn AL, Trivedi MH, O'Neal HA. Physical activity dose-response effects on outcomes of depression and anxiety. Medicine \& Science in Sports \& Exercise. 200133(6 Suppl.), S587-S597; discussion 609-510.

18. Durstine, JL, Haskell WL. Effect of exercise training on plasma lipid and lipoprotenis. Exercise sports sci. Rev1994; 22: 477-522.

19. Krummel D, Etherton TD, Peterson S. Effects of exercise on plasma lipids and lipoproteins of women. ProcSoc Exp Biol Med.1993; 204: 123-37.

20. Superko RH. Exercise training, serum lipids, and lipoprotein particles: is there a change threshold? Med Sci Sports Exerc.1991; 23: 667-85. 